\title{
DRUG-ASSOCIATED STOMATITIS IN METASTATIC COLORECTAL CANCER PATIENTS UNDERGOING AN EPITHELIAL GROWTH FACTOR RECEPTOR INHIBITOR (PANITUMUMAB)E A CASE SERIES
}

\author{
W. Gomes-Silva ${ }^{1}$, A.J. Vechiato Filho ${ }^{1}$, M.C.Q. Oliveira ${ }^{1}$, M.N. Gomes ${ }^{1}$, A.R. Santos-Silva ${ }^{2}$, D.R. Nebuloni ${ }^{3}$, T.B. Brandão ${ }^{1}$ \\ Email: wagner.wgswgs@gmail.com \\ ${ }^{1}$ Instituto do Câncer do Estado de São Paulo, Dental oncology, Sao Paulo, Brazil. \\ ${ }^{2}$ Piracicaba Dental School - State Universisty of Campinas UNICAMP, Oral Diagnosis Department, Piracicaba, Brazil. \\ ${ }^{3}$ Instituto do Câncer do Estado de São Paulo, Clinical Oncology Department, Sao Paulo, Brazil.
}

\section{INTRODUCTION}

Panitumumab $(\mathrm{PmAb})$ is an epithelial growth factor receptor inhibitor (EGFRI) recombinant monoclonal antibody which has been used for advanced metastatic colorectal cancer (mCRC). EGFR, which is expressed in normal and several types of cancer cells, has a pivotal role in promoting cellular proliferation by activation of multiple downstream signaling pathways, including the RAS/RAF/MAPK/PI3K/AKT/mTOR pathway. Therefore, blocking this cell surface protein have demonstrated improved outcomes compared to the previous standard therapies but exclusively in a subset of non-mutated RAS Wild-Type (WT) colorectal adenocarcinomas. Although mucositis/stomatitis has been reported in patients undergoing PmAb for colorectal cancer, no consensus on reporting this phenomenon is available in the literature and the clinical characterization seems to be unclear at this point.

The aim of this study was to report a case series with emphasis on clinical characterization of this oral adverse event associated with PmAb.

\section{METHODS}

A retrospective review of patients' charts which underwent the EGFRI PmAb referred to dental evaluation was conducted. Demographic, medical background and clinical information were recorded for each case. The data analyzed included information about gender, age, tumor location, cancer stage (AJCC, $7^{\text {th }}$ edition) and site of metastasis. Oral affected sites, clinical presentation, time of evolution, local and systemic treatments employed for the oral lesions, as well as follow-up data were assessed from the dental records.

\section{RESULTS}

Over a 4-year period, 6 patients that underwent PmAb and was referred to oral evaluation were identified in medical records. The clinicaldemographic data is presented in table 1 . The oral symptoms appeared in a mean time of 8 days (7-10 days) following irinotecan (IRI) and PamAb combined doses. All patients complained of feed discomfort, 5 patients with moderate pain and 2 patients with mild and severe pain, respectively. All of them presented round/ovoid-shaped shallow ulcerations associated with a surrounding erythematous halo, that showed an aphthous-like appearance. Additionally, 2 patients presented circinate and reddish atrophic tongue lesions that resembled benign migratory stomatitis. The most common affected oral sites were the lips and the tongue (Figure 1). Stomatitis grade 2 and 1 (WHO scale) were recorded for the lesions in 5 patients and in 1 patient respectively. In all, except one case, the oral lesions were accompanied by an acneiform cutaneous rash. The patients were either treated with photobiomodulation or topical corticosteroids with clinical resolution.

\begin{tabular}{|c|c|c|c|c|c|c|}
\hline & Case 1 & Case 2 & Case 3 & Case 4 & Case 5 & Case 6 \\
\hline Gender/Age & $F / 56$ & $M / 37$ & $F / 63$ & $\mathrm{~F} / 50$ & $M / 66$ & $F / 53$ \\
\hline Location & $\begin{array}{l}\text { Colon and } \\
\text { rectum }\end{array}$ & $\begin{array}{l}\text { Ascending } \\
\text { colon }\end{array}$ & $\begin{array}{l}\text { Sigmoid } \\
\text { colon }\end{array}$ & $\begin{array}{l}\text { Sigmoid } \\
\text { colon }\end{array}$ & Rectum & Rectum \\
\hline Stage & IV & IV & IV & IV & IV & IV \\
\hline Metastasis & Hepatic & $\begin{array}{l}\text { Hepatic, } \\
\text { Non- } \\
\text { regional } \\
\text { lymph } \\
\text { nodes and } \\
\text { Peritoneum }\end{array}$ & Hepatic & Hepatic & Hepatic & Hepatic \\
\hline $\begin{array}{l}\text { Cancer } \\
\text { Treatment }\end{array}$ & $\begin{array}{c}\text { mFLOX + RT } \\
+ \text { Surgery + } \\
\text { IRI } \\
\text { monodrug + } \\
\text { IRI and PmAb }\end{array}$ & $\begin{array}{c}\text { mFLOX + } \\
\text { Roswell } \\
\text { Park } \\
\text { regimen 5- } \\
\text { FU + } \\
\text { mFLOX + IRI } \\
\text { monodrug } \\
+ \text { IRI and } \\
\text { PmAb }\end{array}$ & $\begin{array}{c}\text { AA surgery + } \\
\text { mFLOX + IRI } \\
\text { and PmAb }\end{array}$ & $\begin{array}{c}\text { AA surgery + } \\
\text { mFLOX + } \\
\text { Roswell Park } \\
\text { Regimen 5- } \\
\text { FU + mFLOX } \\
+ \text { IRI and } \\
\text { PmAb }\end{array}$ & $\begin{array}{c}\text { mFLOX + RT } \\
+ \text { IRI } \\
\text { monodrug + } \\
\text { IRI and } \\
\text { PmAb }\end{array}$ & $\begin{array}{c}\text { Surgery + } \\
\text { mFLOX + IRI } \\
\text { monodrug + } \\
\text { IRI and } \\
\text { PmAb }\end{array}$ \\
\hline PmAb dose & $\begin{array}{c}400 \mathrm{mg} \\
\mathrm{q} 14 \mathrm{w}\end{array}$ & $\begin{array}{c}600 \mathrm{mg} \\
\mathrm{q} 14 \mathrm{w}\end{array}$ & $\begin{array}{c}300 \mathrm{mg} \\
\mathrm{q} 14 \mathrm{w}\end{array}$ & $\begin{array}{c}300 \mathrm{mg} \\
\mathrm{q} 14 \mathrm{w}\end{array}$ & $\begin{array}{c}500 \mathrm{mg} \\
\mathrm{q} 14 \mathrm{w}\end{array}$ & $\begin{array}{c}400 \mathrm{mg} \\
\mathrm{q} 14 \mathrm{w}\end{array}$ \\
\hline
\end{tabular}

Figure 1. (A-D) Acneiform cutaneous rash and drug-associated stomatitis in patients that underwent PmAb.
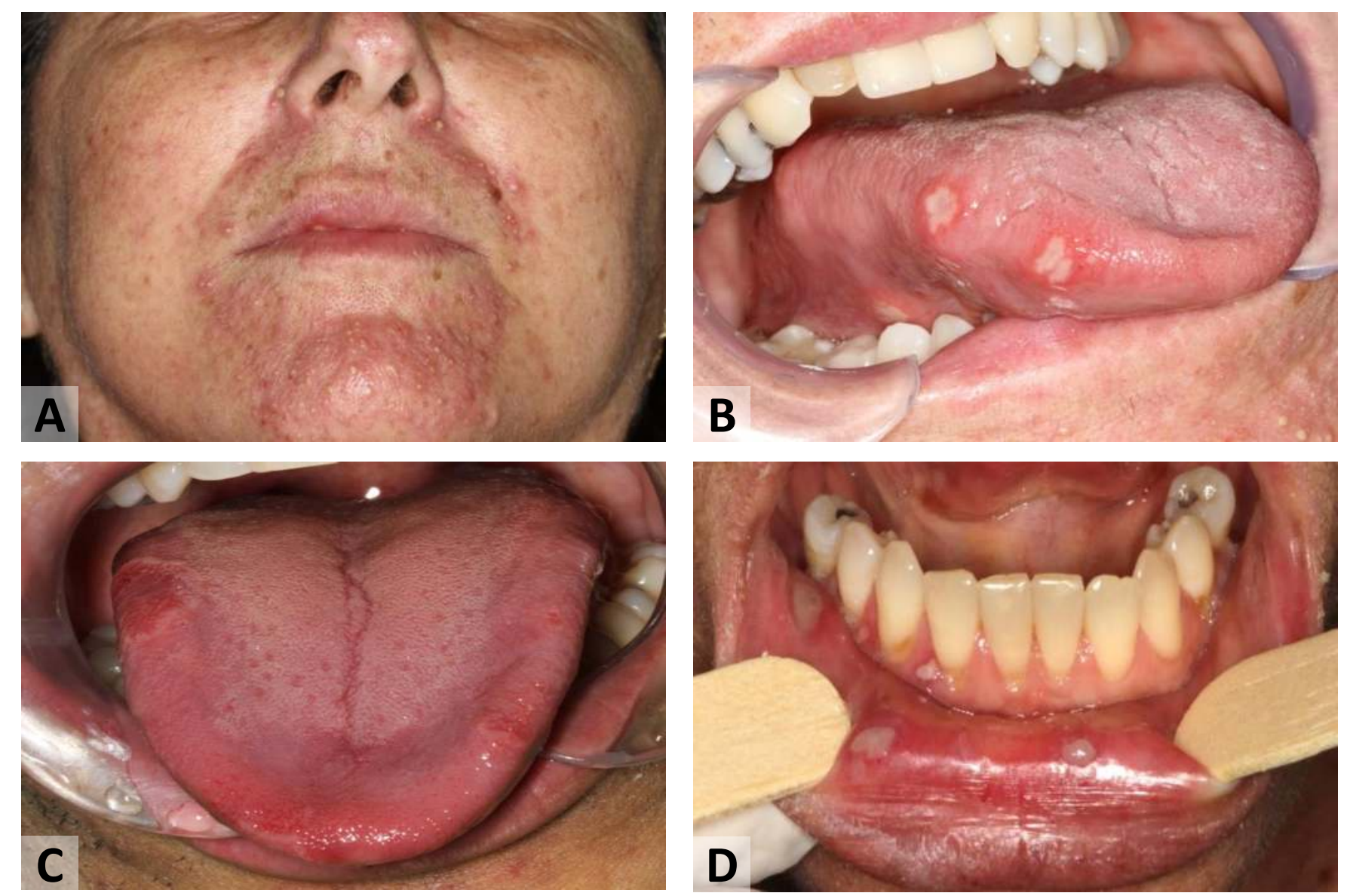

CONCLUSIONS

In summary, we concluded that oral lesions related to PmAb share common features which resemble aphthous and benign migratory stomatitis. Thus, we recommend the use of drug-associated stomatitis for this side effect, similarly to mTOR inhibitor-associated stomatitis.

In addition, it is worth to mention that preventive measures, the early recognition and the correct management of this oral adverse event may be helpful to improve patients' treatment, not only avoiding discontinuation of a life-saving therapy as well as maintaining their quality of life at an adequate level during the cancer treatment course.

\section{REFERENCES}

1.Vigarios E, Epstein JB, Sibaud V. Oral mucosal changes induced by anticancer targeted therapies and immune checkpoint inhibitors. Support Care Cancer. 2017;25(5):1713-39.

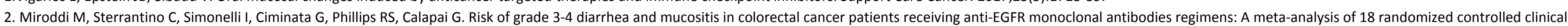
trials. Crit Rev Oncol Hematol. 2015;96(2):355-71. 